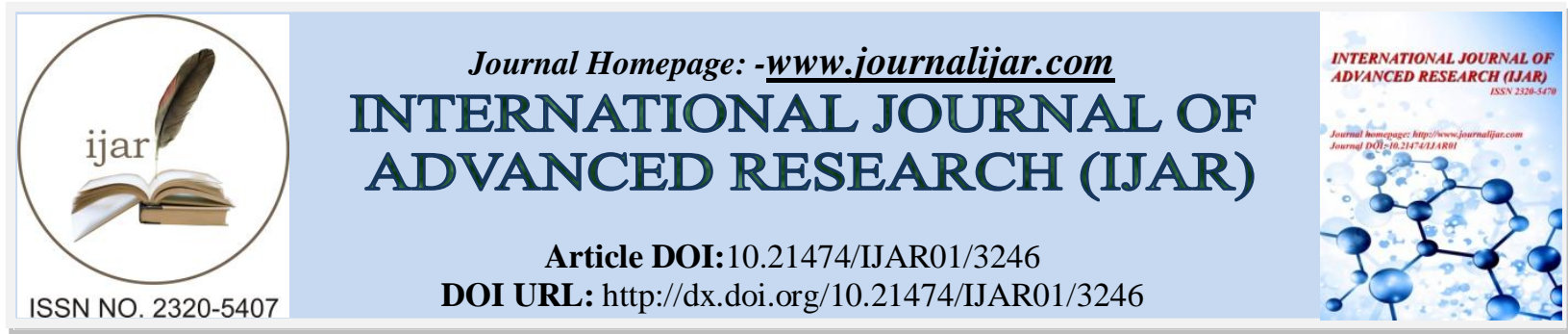

RESEARCH ARTICLE

\title{
KNOWLEDGE, ATTITUDE, AND BEHAVIOR AMONG MEDICAL STUDENT AT UMM- AL-QURA UNIVERSITY TOWARD EVIDENCE-BASED MEDICINE.
}

Naif A Bawazeer M. D ${ }^{1}$, Yazeed N Alotaibi M. D ${ }^{2}$, Nawaf H. Fatani M. D ${ }^{2}$ and Aisha O. Gabra, M.D ${ }^{2}$.

1. Teaching assistant. Faculty of medicine in Umm Alqura University at Makkah, Saudi Arabia.

2. Faculty of medicine, Umm Al-qura University, Makkah, Saudi Arabia.

\section{Manuscript Info}

Manuscript History

Received: 17 December 2016

Final Accepted: 14 January 2017

Published: February 2017

Key words:-

evidence based medicine, knowledge, attitude, behavior and barriers

\section{Abstract}

Objective: This study aims to evaluate the knowledge, attitude and behavior toward evidence based medicine (EBM) among undergraduate medical student in Saudi Arabia and to highlight barriers preventing the use of EBM effectively.

Methods: This cross sectional study was conducted on sixth year medical students at Umm Al-Qura University (UQU) by distributing a self-administered questionnaire manually and electronically between November 2014 to January 2015.

Results: The survey completed by only $32.5 \%(n=87)$ students, all sixth year medical students at UQU showed a good knowledge and a positive attitude towards evidence based medicine. Most of the students find their evidence on the internet, while $52.9 \% \quad(n=64)$ never used reliableand peer reviewed sources (Cochrane database) in their searches. There are $58 \%$ of student who spend an hour or less daily looking up evidence, while $32.2 \%(\mathrm{n}=28)$ do not spend any time during their usual day. Lastly, $65 \%$ believe that EBM takes too much time for busy medical students and only $29.9 \%$ believed that EBM is clearly incorporated during teaching sessions.

Conclusion:Good level of knowledge and positive attitude towards evidence based medicine was reported by the students. On the other hand, there is a gap in their actual behaviors of practicing EBM. Accordingly, improvement on education system of EBM is needed to increase the quality and effectiveness of student's skills and their ability of applying EBM in their future by incorporate the EBM in various teaching activities. Further studies are required on a larger scale for generalizing the results.

Copy Right, IJAR, 2017,. All rights reserved.

\section{Introduction:-}

Evidence-based medicine is defined as a particular approach that incorporate the patient values, the best available scientific evidence, and clinical expertise. ${ }^{1}$ Since there's a great discrepancies between the huge variety of the new updated information and health care practice, the need of evidence based medicine is becoming mandatory among physician and undergraduate health care provider. ${ }^{2}$

Corresponding Author:-Naif A Bawazeer M. D. 
Practice supported by evidence usually improves the outcomes. There is a clear improvement in the quality of care given to the patientsalongwithcost and results satisfaction as well as physician gains better clinical judgment and decision making with EBM practice. ${ }^{3}$ One of the key elements to fully applied evidence based medicine is having a good grasp on the use of searching techniques on databases, in order to obtain trustworthy and reliable information and also greatly helps in overcoming the difficulties and diversity in the medical literature. ${ }^{4}$

Weak understanding of statistic and EBM concepts were found in many medical students and physicians which reflected as a barrier in practicing evidence based medicine, thus many countries felt the need to implement lectures and materials in their curriculum regarding the evidence based medicine. In addition to some other hindrances to effectively teach and use EBM on daily basisare lack of access to the materials needed to engage EBM, and more importantly the lack of time. ${ }^{5,6}$

Since EBM had been greatly emphasized in medical sciences, therefore assessing and identifying the factors that affect its proper use is essential. Taking all this into account this study examine the perception, knowledge and attitude among undergraduate sixth year medical student at Umm- Al-Qura university, in order to determine the current attitude of the students and to highlight the main barriers preventing the use of EBM effectively as daily practice.

\section{Materials and Methods:-}

This cross-sectional study was conducted by distributing a questionnaire among 6th year medical students from Umm Al-Qura University, Makkah, Saudi Arabia, to assess the level of awareness toward evidence based medicine (EBM), the data collection carried out from November 2014 to January 2015. Both males and females were included as they had completed their academic curriculum and clinical rotations, 325 students in total (161 males and 164 females).

The questionnaires were distributed to the students by two methods. First, a questionnaire manually distributed to the students in their classroom. After that, an electronic one, shared through Google Form and their personal emails. They were requested to use, one of the two methods. Informed consent were taken, for the voluntary participation and their personal information will be confidential. The ethical approval was obtained from Ethics Committeefor Scientific Research at the college of medicine, Umm Al-Qura University prior to conducting this study.

In this study a descriptive survey entitled " knowledge, attitude, and behavior questionnaire (KAB questionnaire) " have been used, which is a valid questionnaire to assess the awareness about the evidence based medicine, particularly for undergraduate medical student, as it cover the students' perspective regarding their knowledge, attitude and behavior toward evidence base medicine.

The KAB questionnaire is derived from a comprehensive literature review by Dr. Janice M Johnston and other experts, and permission was granted from the authors to use this questionnaire, and to edit as suitable to make other correlations. The internal reliability for this survey with Cronbach's alpha is $0.71-0.88$. The questionnaire had 43 questions and we added questions regarding the students' cumulative GPA and their previous exposure to EBM education or practice. The measurement of Construct validity wasbycorrelating the factors with other measures of EBM.Responsiveness of the questionnaire was testedthrough paired t-tests ofthe pre-factor and postfactormean scores (Johnston et al., 2003; Brown et al., 2010). Responsiveness was reported to be reliable andvalid (Johnston et al., 2003). Data entry and statistical analysis was done using SPSS version 20.

\section{Results:-}

Our total population is 268 of sixth year students at UQU medical college, 127 students were males and 141 females. Of the responders, only 87 students completed the EBM-KAB questionnaires. Out of these, 46 were males and 41 females, GBA of the majority of the students (47.1\%) were less than 3.0, and (18.9\%) 3.0 or more. Overall, 56 students were previously exposed to EBM; 37 students during curriculum, 13 from attended an extra curriculum lecture, and formal EBM training (certified courses) for 6 students. On the other hand, 21 students without previous exposure to EBM.

Most students $67.7 \%(\mathrm{n}=59)$ have a clear understanding of what evidence-based medicine means. And 73.5\% ( $\mathrm{n}=64)$ agreed that effective searching skills, accessible bibliographicdatabases, and evidencesources are essential to 
practicingEBM. Almost $80 \%(\mathrm{n}=70)$ were aware that to determine the quality of research, critical appraisal skills is needed. When asked how frequently they access to medical evidence in general, majority of students $29.9 \%(\mathrm{n}=26)$ access every month, $21.8 \%(n=19)$ every week, and only $4.6 \%(n=4)$ every day. While $22 \%(n=19)$ reported had neveraccessed to medical evidence. Table 1 shows thefrequent accessing, to different sources of medical evidence.

Compared to one year ago, 24 students reported that they now looked up evidence as information relating to the patient's condition approximately for 2-3 times, during or after clerking each patient on the ward or in the clinic, 22 only one time, and 20 did not look up for evidence.

Fifty-one students spent 1 minute to an hour, every day to find or look up evidence, compared to the previous year, this time does not include their study time. In addition, when they clerked a patient, 47 students took up to 30 minutes to look up the evidence relating to his/her illness, and the remaining 40 students did not look up evidence for their patient, this time was only spent onretrieving the evidence material. Moreover, about $30 \%(\mathrm{n}=26)$ students believed that EBM practice can affect the management or outcome of their patients. Furthermore, it was found that most $59.7 \%(\mathrm{n}=52)$ students familiar to use internet as source when looking up for evidence after clerking a patient, while only $8 \%(\mathrm{n}=7)$ students were using text book. The percentage of using different sources of evidence after clerking a patient shows in figure 1.

They were asked about how much they felt that evidence increasing their understanding of the disease or condition. It was found that $20.7 \%(\mathrm{n}=18)$ reported that the evidence increased their knowledge by over $80 \%, 31 \%(\mathrm{n}=27)$ noted an increase of between $61 \%$ and $80 \%$, and other $31 \%(\mathrm{n}=27)$ stated an increase up to $60 \%$. Fifteen students $(17.2 \%)$ reported an increase in understanding by $40 \%$ or less whenusing EBM.

Regarding the frequency of raising the role of current best evidence atclinical rounds/sessions, the students answers showed $15.1 \%(\mathrm{n}=13)$ never, $65.4 \%(\mathrm{n}=57)$ sometimes, and $19.5 \%(\mathrm{n}=17)$ often.During teaching rounds or bedside teaching, 29.9\% $(\mathrm{n}=26)$ of students reported that when discussinga particular clinical problem, current best evidence is moderately used, and $35.6 \%(\mathrm{n}=31)$ were prepared for the clinical teaching sessions in the last month, while the majority $60.9 \%(\mathrm{n}=53)$ were unprepared.

Almost $27 \%(\mathrm{n}=24)$ have changed the way they learn after practicing of evidence based medicine, similar number considered the practice of EBM is somewhat a routine part of their learning. However, $42.5 \%(n=37)$ believed they have some confidence to clinical decision-making. Most 78.1\% $(\mathrm{n}=68)$ believed that EBM will be useful in future practice as doctor, and $72.3 \%(\mathrm{n}=63)$ are willing to practice evidence based medicine as a doctor in the future. Table 2 shows details students' answers toward EBM practice. Fifty-one students $(61 \%)$ agreed It is easy to find the evidence in order to practice evidence-based medicine while $39 \%(\mathrm{n}=32)$ disagreed, 57 students $(65 \%)$ believe that EBM takes too much time for busy medical students, on the other hand $78.2 \%(\mathrm{n}=68)$ agreed that evidence based medicine should be an integral part of the undergraduate medical curriculum. Table 3 outlines a summary of students responds to other EBM attitudinal questions.

Table 1:-TheDifferent Sources That Used to Access to Medical Evidence.

\begin{tabular}{|c|c|c|c|}
\hline & $\begin{array}{c}\text { Every day, and } \\
\text { Otherday) } \\
\mathrm{N}(\%)\end{array}$ & $\begin{array}{c}\text { Every (month, and } \\
\text { week) } \\
\mathrm{N}(\%)\end{array}$ & $\begin{array}{c}\text { Never } \\
\mathrm{N}(\%)\end{array}$ \\
\hline $\begin{array}{c}\text { Internet } \\
\text { (excludingMEDLINE and Cochrane Reviews) }\end{array}$ & $17(19.6)$ & $53(60.9)$ & $17(19.5)$ \\
\hline Original research papers & $9(10.3)$ & $41(47.1)$ & $37(42.5)$ \\
\hline Textbooks & $18(20.7)$ & $39(44.8)$ & $30(34.5)$ \\
\hline Cochrane database & $10(11.5)$ & $31(35.6)$ & $46(52.9)$ \\
\hline $\begin{array}{c}\text { ACP Journal Club, the journal Evidence-Based } \\
\text { Medicine, POEMs (Patient-oriented evidence that } \\
\text { matters) or CATs (Critically appraised topics) }\end{array}$ & $14(16.1)$ & $28(32.2)$ & $45(51.7)$ \\
\hline InfoRetriever & $16(18.4)$ & $26(29.9)$ & $45(51.7)$ \\
\hline
\end{tabular}


Table 2:- Details Answers toward EBM Practice.

\begin{tabular}{|c|c|c|c|}
\hline & $\begin{array}{c}\text { A lot, } \\
\text { andcompletely } \\
\mathrm{N}(\%)\end{array}$ & $\begin{array}{l}\text { A little, somewhat, and } \\
\text { moderately } \\
\mathrm{N}(\%)\end{array}$ & $\begin{array}{l}\text { Not at all } \\
\mathrm{N}(\%)\end{array}$ \\
\hline $\begin{array}{l}\text { The effect of practicingtheEBM, on your patient's } \\
\text { management and outcome }\end{array}$ & $32(36.8)$ & $48(55.2)$ & $4(4.6)$ \\
\hline $\begin{array}{l}\text { The frequent of discussion about the best evidence, } \\
\text { related to the patient's condition (during teaching } \\
\text { settings) }\end{array}$ & $15(17.2)$ & $64(73.6)$ & $8(9.2)$ \\
\hline $\begin{array}{l}\text { Considering the practice of EBM, as routine part of the } \\
\text { learning process }\end{array}$ & $20(23.1)$ & $59(67.8)$ & $5(5.7)$ \\
\hline The influence ofEBM practice, over the way you learn & $27(31)$ & $52(59.8)$ & $4(4.6)$ \\
\hline
\end{tabular}

Table 3:- Summary of Students Responds to Different EBMAttitudinal Questions.

\begin{tabular}{|l|c|c|}
\hline \multicolumn{1}{|c|}{ Attitudinal Questions } & Agreen(\%) & Disagreen(\%) \\
\hline EBM is a "cook-book" medicine that disregards clinical experience. & $53(60.9)$ & $34(39.1)$ \\
\hline $\begin{array}{l}\text { No personal reason to adopt EBM, because it is just a "fad" (or } \\
\text { "fashion") that will pass with time. }\end{array}$ & $25(28.7)$ & $62(71.3)$ \\
\hline $\begin{array}{l}\text { EBM is the future of clinical medicine and will become the standard of } \\
\text { care. }\end{array}$ & $66(75.9)$ & $21(24.1)$ \\
\hline $\begin{array}{l}\text { The validity ofEBM,makesanyone can see patients and do what doctors } \\
\text { do. }\end{array}$ & $34(39.1)$ & $53(60.9)$ \\
\hline EBM ignores the "art" of medicine & $36(41.3)$ & $51(58.7)$ \\
\hline $\begin{array}{l}\text { EBM should not be practice, in general, because medicine is about } \\
\text { people and patients, not statistics. }\end{array}$ & $20(22.9)$ & $67(77.1)$ \\
\hline $\begin{array}{l}\text { Choosing the best treatment for a patient, bywork experiences is more } \\
\text { important than a research findings, }\end{array}$ & $39(44)$. & $48(55.2)$ \\
\hline $\begin{array}{l}\text { Appreciating the advantages of practicing EBM. } \\
\text { Personal observation and experience, that EBM is being practiced } \\
\text { currently in Saudi Arabia }\end{array}$ & $62(71.2)$ & $25(28.8)$ \\
\hline
\end{tabular}

Figure 1: Percentage of Using Different Sources of

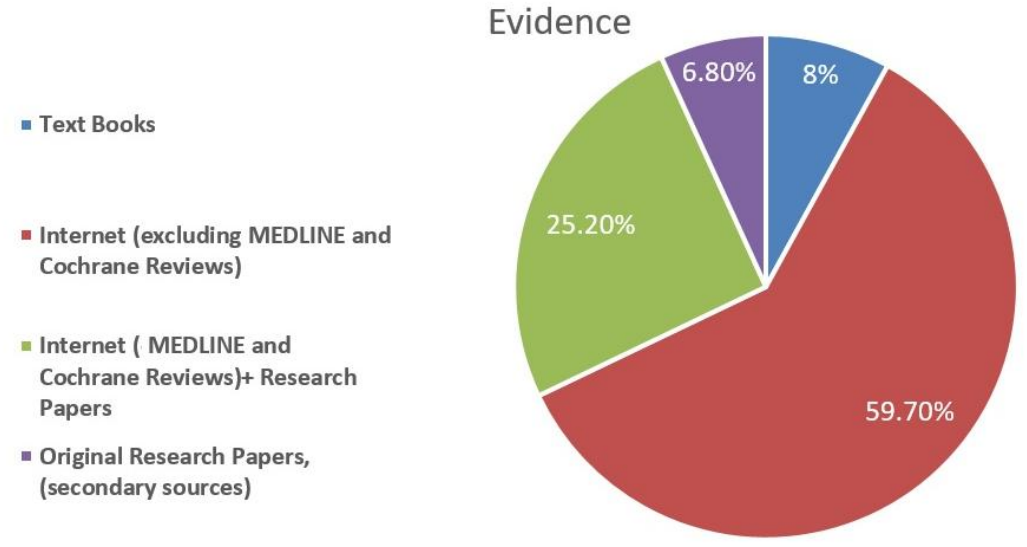

\section{Summary of Results:-}

Overall, all 87 of sixth year medical students at UQU, showed a good knowledge and a positive attitude towards evidence based medicine, 37 of them were previous exposed to EBM during curriculum, $58 \%$ of them spent up to 1 hour, every day to find or look up evidence, In addition, when they clerked a patient, 47 students take 30 minutes in 
maximum to look up the evidence relating to his/her illness, it is found that $59.7 \%(\mathrm{n}=52)$ students more familiar to use internet when looking up for evidence after clerked a patient.

\section{Discussion:-}

This study was designed to evaluate the knowledge, attitude and behavior toward EBM among medical students. There are multiple modalities to teach EBM as mentioned in the literature: workshops, journal clubs, the problembased method, or the integration in the curriculum in the basic science and clinical years. ${ }^{7} \mathrm{Umm} \mathrm{Al}-$ Qurauniversityuse integration of EBM in the clinical years curriculum as the modality of teaching EBM. The target participants in this study were the final sixth year medical students because they were exposed to clinical training and bedside teaching since fourth year, in addition to their supposed familiarity with EBM concept and practice.

Majority of participants $76.7 \%$ ( $n=67$ ) declared that they have a clear understanding of what is the concept of EBM. This good percentage reflects the college's plans as(Research and evidence) module has been considered as a vertical module in the new reformed curriculum at the faculty of medicine in Umm Al-Qura University. Vertical modules were designed to deliver holistic understanding of medical phenomena and cases, while being studied through the curriculum from the second year till the sixth year.

Forty-two percent of the participants $42.5 \%(\mathrm{n}=37)$ stated that their previous exposure was only during the curriculum, while there are $24.1 \%(n=21)$ claimed that they never exposed to EBM before. Our students have been exposed to EBM, according to the curriculum's objectives and plans, but still small proportion do not realize the integration of EBM in the curriculum, for unclear reasons. Therefore, more efforts are needed to clarify this integration in their daily education. $14.9 \%(\mathrm{n}=13)$ attended an extracurricular lecture and only $6.9 \%(\mathrm{n}=6)$ got formal EBM training in certified courses. Barghouti et al. concluded that 2-week short, intensive course in EBM conducted on fifth year medical students had significantly improved their EBM skills and knowledge. ${ }^{8}$

Low levels of knowledge about EBM were reported among Persian medical students and Omani medical residents. ${ }^{9}$

${ }^{10}$ In Ireland, occupational therapy students were knowledgeable and aware of the required EBM skills. ${ }^{11}$ In Netherland, Scholten-peeters et al compared the level of EBM knowledge in four groups: physical therapy students, their teachers, supervisors and physical therapist, they found that the highest level is in the teachers' group while students ranked their knowledge from insufficient to average. ${ }^{12}$ Johnston et al. reported lower score for medical students in second and third yearscompared to their colleagues in fifth year. ${ }^{13}$

Over half of the participants 59.8\% find their evidence on the internet (excluding MEDLINE and Cochrane Reviews), $25.3 \%$ on the internet and research papers, $6.9 \%$ from original research papers and secondary sources. Only, $8.1 \%(\mathrm{n}=7)$ use textbooks as a source of evidence. Students in this study are not aware enough about the value of using a peer reviewed sources as well as the important of extracting the information from reliable source like Cochrane library or PubMed search engine, instead they rely on easy access sites from the internet, despite that Cochrane library is considered as the main source of systemic reviews and meta-analyses. ${ }^{9}$ That's why it is a must to support and encourage students to adapt this important concept during their search and to get familiar with such databases and overcoming the difficulties and diversity in the medical literature. Similarly, some studies reported that many students still rely on textbooks and seniors' opinion mainly to solve clinical problems. ${ }^{12}$

Most of Irish occupational therapy students reported that they were prepared with evidence when they were on the fieldwork placement, which indicate their positive attitude and effective behaviors to practice EBM. ${ }^{11}$ Also, many other studies reported the same positive attitudes toward EBM by undergraduate students. ${ }^{12-14}$

In the view of EBM current practicing, 52.9\% look up evidenceduring or after clerking each patient in the ward or the clinic. While, last third 23\% do not look up for any evidence at all. It is recommend that the academic educators to consider EBM practicing as an essential part of daily sessions and their objective during the exams in order to evaluate the required skills and knowledge levels on periodic occasions as well as to illustrate the way of using EBM in relation to clinical experiences under various clinical scenarios.

More than half of participants spend an hour or less daily finding or looking up evidence while $32.2 \%$ do not spend any time during their usual day looking up evidence. Furthermore, $65 \%$ students believe that EBM takes too much time for busy medical students. So encourage the students to use EBM on a regular basis during their bedside training along with teach them how to search the available databases effectively to get the updated evidences in 
minimal time is very important.In Umm Al-Qura University, good resources and access for many publishers are available, but there is a need to periodic classes to guide students on how to search effectively the available databases. Stronge and Cahill found that over half of occupational therapy students assessed evidence every day or every other day and only one third of them spend over than an hour looking up evidence. ${ }^{11}$ Johnstonet al, reported positive correlation between the future use of EBM and the frequency of practicing EBM and the need of evidence per day. ${ }^{13}$

Among many studies discussing teaching EBM effectively, only a few ones focused on how medical student perceive, utilize and apply their EBM knowledge in clinical practice. ${ }^{7}$ In Saudi Arabia this study is one of the very few studies to assess undergraduate's perception of EBM with using a tested questionnaire for its reliability and validity.KABquestionnaireis considered one of the view tools developed specifically to assess undergraduates EBM knowledge, attitude and behavior. ${ }^{13}$ Never the less, out of the 268 questionnaires that had been distributed, only 87 studentsparticipated voluntarily with response rate of $32.5 \%$, which was much lower compared to Johnstonet al ( author of the KAB questionnaire) whoreported $99 \%$ response rate amongfifth year medical students in Hong Kong university as they found that response rate to be higher in fifth year medical students compared to their colleagues in second and third years. ${ }^{13}$ In addition, Scholten et al. and Al-amrani et al. reported even lower response rates than this study ( $20 \%$ and $21 \%$ response rates consecutively). ${ }^{12}$ From authors point of view, this low response rate mainly due to the long list of questions (43 questions in 5 pages), this questionnaire took about 12 to 15 minutes to be completed. In addition, a major part of the students returned the questionnaire with uncompleted questions especiallyfrom the last page. Never the less, other factor could play a role like high workload of students, method and timing of distribution. The knowledge and skills of evidence base medicine and its integration in the learning process and application on the clinical practice is a highly complex and dynamic process that cannot be easily measured and analyzed. The use of subjective questionnaire (as KAB- questionnaire) could give a biased results than the actual situation. Despite that there are many tools which designed to measure this process, an objective and easy to use assessment of EBM is needed to address the actual level of the required skills and knowledge among student.

The low response rate and the fact that this is a cross-sectional study, may have affected the generalizability of the results which limit the representativeness of our data. Therefore, we advise that our data must be interpreted with cautions. In addition, the long term effects mastry of EBM behaviors among our students still unkown and need to be evaluated by robust assment tools. Therefore, logutidinal study with different subsets and multiple occasions is stongly recquired.

\section{Recommendations:-}

In a previous study conducted among physicians in Saudi Arabia, lack of knowledge and basic skills were the main barriers to implement EBM in clinical practice. ${ }^{15}$ Al-Almaie et al. found the lack of training in EBM to be the major barrier in Dammam region. ${ }^{15}$ In Asir region, Khoja and Al-ansary reported the patient overload and unavailability of a local library are the main perceived barriers. ${ }^{16}$ In another study in Riyadh region, Khoja and Al-ansary found the patient overload and lack of personal time to be the two main barriers. ${ }^{17}$ In Western region,Al-Omari and Al-Asmary found that the unavailability ofdistributed updated clinical letters, journals or guidelines is the major barrier to practice EBM. ${ }^{18}$

Accordingly, the authors emphasize on the importance of teaching and applying EBM effectively to undergraduates and insuring that they have the required knowledge and skills to bring EBM to real clinical practice with confidence. Therefore, it is recommended to incorporate the EBM in various teaching activities such as: small group teaching, task assignment, morning meetings, ward rounds and journal club with continued evaluation by academic educators. ${ }^{19}$ Furthermore, the academic educators have to become EBM role models themselves for the student. ${ }^{20}$ Also, training students to search effectively the available resources like electronic and online databases of systemic review and EBM summaries on daily or weekly bases is an important element in teaching. ${ }^{21}$ Further studies are needed to assess how viable is the educational curriculum to prepare the Saudi medical graduates with EBM practice to meet the Saudi community health needs.

\section{Conclusion:-}

This study gives us an insights into the knowledge, attitude and behavior toward EBM of sixth year medical students at UQU as well as small representation of Saudi Arabia, which shows that the majority were knowledgeable and have a positive attitude. However, improvement and focusing on EBM education system in pre-graduate student, 
both are needed to increase the qualityand the effectiveness of student's skills as well as their ability to apply EBM in the future, and further studies are required on a larger scale for precise identification of the problems in order to improve the quality of our graduates.

\section{Reference:-}

1. West CP, McDonald FS. Evaluation of a longitudinal medical school evidence-based medicine curriculum: a pilot study. Journal of General Internal Medicine 2008; 23(7): 1057-9.

2. Bradt P, Moyer V. How to teach evidence-based medicine. Clinics in Perinatology 2003; 30(2): 419-33.

3. Swanson JA, Schmitz D, Chung KC. How to practice evidence-based medicine. Plastic and Reconstructive Surgery 2010; 126(1): 286-94.

4. Dickersin K, Straus SE, Bero LA. Evidence based medicine: increasing, not dictating, choice. British Medical Journal 2007; 334(Suppl 1): s10.

5. Coomarasamy A, Khan KS. What is the evidence that postgraduate teaching in evidence based medicine changes anything? A systematic review. British Medical Journal 2004; 329(7473): 1017.

6. Slawson DC, Shaughnessy AF. Teaching evidence-based medicine: should we be teaching information management instead? Academic Medicine 2005; 80(7): 685-9.

7. Alahdab F, Firwana B, Hasan R, Sonbol MB, Fares M, Alnahhas I. Undergraduate medical students , perceptions, attitudes, and competencies in evidence-based medicine ( EBM ), and their understanding of EBM reality in Syria. 2012;

8. Journal AI, Barghouti FF, Yassein NA, Jaber RM, Khader NJ, Shokhaibi S Al, et al. Short Course in EvidenceBased Medicine Improves Knowledge and Skills of Undergraduate Medical Students: A Before-and-After Study Short Course in Evidence-Based Medicine Improves Knowledge and Skills of Undergraduate Medical Students : A Before-and-After. 2013;1334(August 2016):7-11.

9. Ghahremanfard F, Nassaji M, Mirmohammadkhani M, Tanha A. Knowledge and attitude toward evidencebased medicine among medical students in Semnan, Iran. 2014;7:32-7.

10. Al-amrani K, Al-khabori M. Knowledge and Attitudes of Oman Medical Specialty Board Residents towards Evidence-Based Medicine. 2014;29(3):178-84.

11. Stronge M, Cahill M. Self-reported Knowledge, Attitudes and Behaviour towards Evidence-based Practice of Occupational Therapy Students in Ireland. 2012;19:7-16.

12. Scholten-peeters GGM, Beekman-evers MS, Boxel ACJW Van, Hemert S Van, Paulis WD, Wouden JC Van Der, et al. Attitude, knowledge and behaviour towards evidence-based medicine of physical therapists , students , teachers and supervisors in the Netherlands : a survey. 2013;19:598-606.

13. Johnston JM, Leung GM, Fielding R, Tin KYK, Ho L. The development and validation of a knowledge , attitude and behaviour questionnaire to assess undergraduate evidence-based practice teaching and learning. 2003;992-1000.

14. Pruskil S, Burgwinkel P, Georg W, Keil T, Kiessling C. Medical students ' attitudes towards science and involvement in research activities: A comparative study with students from a reformed and a traditional curriculum. 2009;

15. Al-almaie SM, Al-baghli N. Barriers Facing Physicians Practicing Evidence-Based Medicine in Saudi Arabia. 2004;24:163-70.

16. Ahmadi S, Baradaran HR, Ahmadi E. Effectiveness of teaching evidence-based medicine to undergraduate medical students : A BEME systematic review. 2015;21-30.12.

17. Al-ansary LA, Khoja TA. The place of evidence-based medicine among primary health care physicians in Riyadh region, Saudi Arabia. 2002;19(5):537-42.

18. Al-omari FK, Al-asmary SM. Attitude, awareness and practice of evidence based medicine among consultant physicians in Western region of Saudi Arabia. 2006;966(May):1887-93.

19. Ferwana M, Alwan IA, Moamary MA, Magzoub ME, Tamim HM. M edical Education Integration of evidence based medicine into the clinical years of a medical curriculum. 2012;19(2):136-41.

20. Arabia S, Faisal K, Hospital S, Arabia S. Towards Evidence-Based Medical Education in Saudi Medical Schools. 2006;26(December):429-32.

21. Gruppen LD, Rana GK, Arndt TS. A Controlled Comparison Study of the Efficacy of Training Medical Students in Skills. 2005;80(10):940-4. 